\title{
Effects of Thermomechanical Treatment on the Occurrence of Coincident Site Lattice Boundaries in High Strength Low Alloy Steel
}

\author{
Renato Soares de Castro $^{\mathrm{a}, \mathrm{b}}$, Ricardo Artur Sanguinetti Ferreira ${ }^{a *}$, Igor Rafael Vilarouco Pedros $a^{\mathrm{a}, \mathrm{b}}$, \\ Yogendra Prasad Yadava \\ ${ }^{a}$ Department of Mechanical Engineering, Federal University of Pernambuco - UFPE, Recife, PE, Brasil \\ ${ }^{\mathrm{b}}$ Departament of Mechanical, Federal Institute of Education, Science and Technology of \\ Pernambuco - IFPE, Recife, PE, Brasil
}

Received: November 28, 2012; Revised: June 7, 2013

\begin{abstract}
Many studies propose thermomechanical routes to improve HSLA (high strength low alloy) steels by microstructural modification but ignore the study of occurrence of CSL boundaries. The occurrence of these special boundaries is influenced by thermomechanical treatment in which the modification of misorientation profile is related with the increase of $\Sigma 3$ and $\Sigma 11$ boundaries and inhibition of $\Sigma 5 \Sigma 7$ and $\Sigma 9$ ones. The formation of $\Sigma 3$ boundaries, beneficial to improve strength, is highly stimulated by this treatment in which deformation plays an important role in the development of CSL boundaries.
\end{abstract}

Keywords: HSLA steel, thermomechanical treatment, acicular ferrite, coincident site lattice

\section{Introduction}

In recent years studies have led attention to CSL (Coincident Site Lattice) boundaries, mainly to investigate the influence of special boundaries in metallic material properties $^{1-3}$. The development of special boundaries has been frequently achieved by annealing treatments. Many of these studies are concerned to stainless steel ${ }^{3}$, where low $\Sigma$ boundaries should be beneficial to minimize crack corrosion mainly due to the low energy of those boundaries. Otherwise low attention has been taken to the occurrence of CSL boundaries in HSLA (High Strength Low Alloy Steel) steel. Many authors have investigated the relationship between thermomechanical treatment and improvement of mechanical properties ${ }^{4-6}$ relating this improvement to the presence of particular microstructure, such as acicular ferrite. HSLA steels with acicular microstructure achieve good properties combination, such as high strength, excellent toughness and superior fatigue behavior ${ }^{7,5}$. Many studies propose thermomechanical routes to improve microstructural changes in HSLA steel but ignore the occurrence of CSL boundaries. This work investigates the misorientetion boundary profile and occurrence of CSL boundaries in HSLA X80 steel submitted to thermomechanical treatment for increasing toughness by microstructural modification.

\section{Experimental Procedure}

The material used in this experiment was an HSLA steel composed of (wt. \%) C 0.07 - S 0.004 - Al 0.036 - Si 0.27 - P 0.016 - Ti 0.018 - V 0.022 - Cr 0.017 - Mn 1.55 - Ni 0.01 - Cu $0.01-\mathrm{Nb} 0.069-\mathrm{Mo} 0.19$. Samples were produced in the form of strips with dimensions of $100 \times 9.5 \times 6.0 \mathrm{~mm}$. The

*e-mail: ras@ufpe.br faces to be rolled were finished with $6.0 \mathrm{~mm}$ thickness and tolerance of $\pm 0.2 \mathrm{~mm}$.

Samples were heated in electrical furnace until $950{ }^{\circ} \mathrm{C}$, maintained for $900 \mathrm{~s}$ and then hot rolled at non recristalization temperature of austenite by a duo rolling cylinder at a strain rate of $1,8 \mathrm{~s}^{-1}$. The rate in applied strain varied from $10 \%$ to $35 \%$.

SEM images were obtained from cross sections of samples submitted to standard metallographic preparation and finally etched with nital at $3 \%$. EBSD analysis were performed in a JSM-5900LV JEOL microscope with Channel 5 software (HKL Company) for data acquisition and data analysis. Samples for EBSD were sanded in $1500 \mathrm{MESH}$ sandpaper and polished with diamond paste. To eliminate possible surface deformations produced by grinding and mechanical polishing, samples were finally polished in colloidal silica of $1 \mu \mathrm{m}$ for $7.2 \times 10^{3} \mathrm{~s}$. Micro hardness Vickers test was carried out with load of $0.1 \mathrm{~kg}$ for $15 \mathrm{~s}$. For each sample five measurements were performed on the central axis of the specimen.

\section{Results and Discussions}

As-received steel had a microstructure with welldefined polygonal ferrite grains with average grain size of $3.6 \pm 0.3 \mu \mathrm{m}$ as shown in Figure 1a. After thermomechanical treatment, the predominance of polygonal ferrite in microstructure was eliminated. The sample deformed at $10 \%$ presented the morphology of a chaotic structure with lamellar and acicular aspects (Figure 1b), which literature has reported as acicular ferrite ${ }^{8-10}$. In samples deformed at $25 \%$ and $35 \%$ (Figures 1c, d) predominant presence of acicular ferrite was more evident, characterized by bundles of ferritic laths interwoven in a chaotic distribution. 

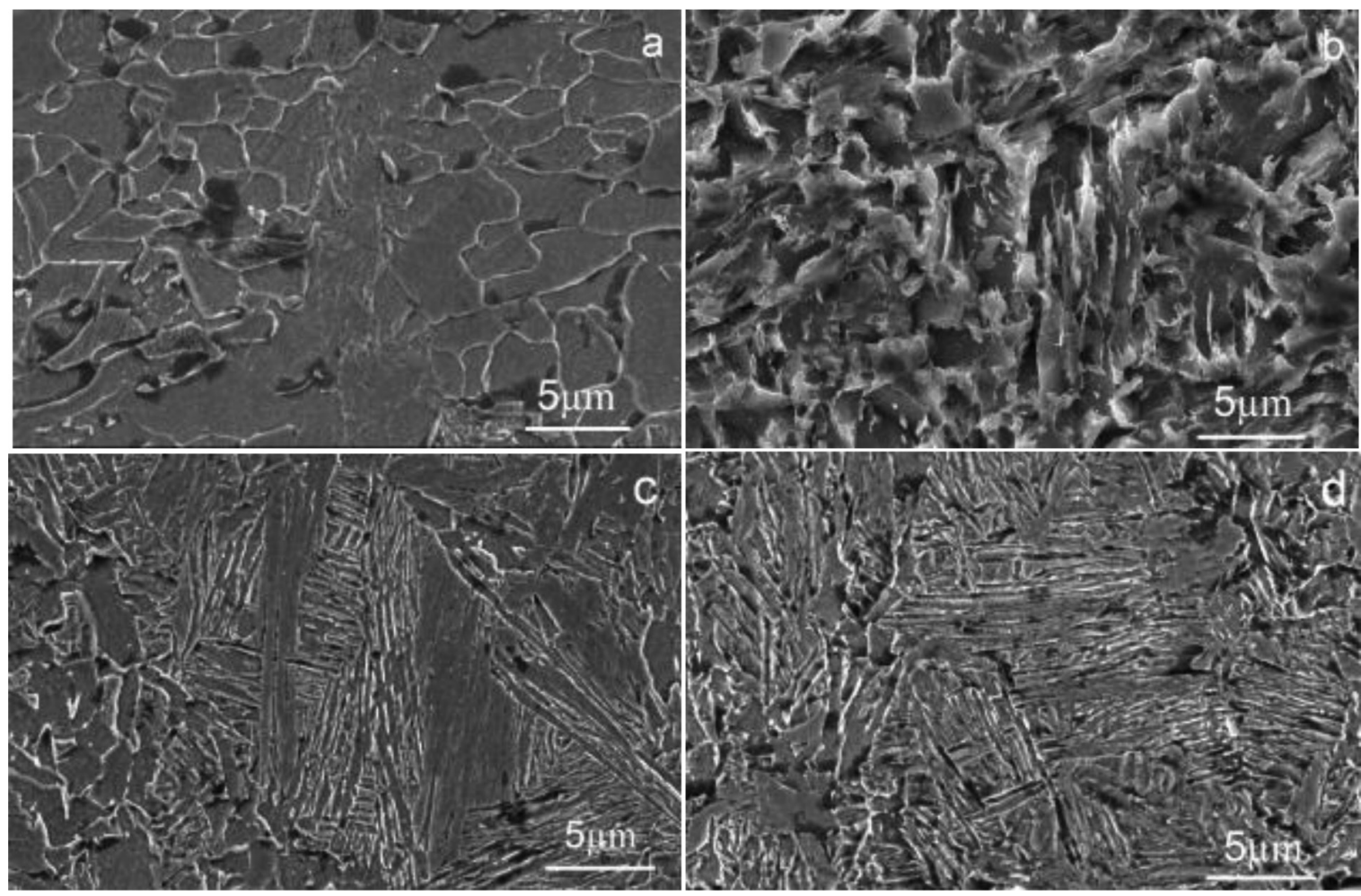

Figure 1. Micrographs of as-received steel and treated samples: (a) as-received (b) deformed at 10\%, (c) deformed at 25\%, (d) deformed at $35 \%$.

The change from polygonal to acicular microstructure increases strength and toughness in steel ${ }^{11}$ due to finer grain size, higher density of dislocations and presence of subunits in acicular ferrite ${ }^{7}$. Results of Vickers hardness test in Table 1 confirm the trend of increasing yield strength due to increasing hardness in treated samples when compared to the as-received material.

Predominance of acicular ferrite, in specimens more intensely deformed, can be attributed to plastic deformation of austenite below non recristalization temperature ${ }^{4}$ which for this steel is around $1100{ }^{\circ} \mathrm{C}$. The high density of dislocations in deformed austenite seems to be beneficial to the formation of acicular ferrite to the detriment of the nucleation of bainite. Plastic deformation of austenite suppresses the formation of the bainitic structure from the grain boundaries and favors the formation of acicular structure stimulated by intragranular nucleation ${ }^{4}$.

It can be observed in the grain boundaries map (Figure 2) the evolution from a regular and well-designed grain shape microstructure in as-received steel (Figure 2a) to a finer and less regular one in the sample submitted to thermomechanical treatment (Figure 2b). It can be seen, from histograms in Figure 3a, b, that as-received steel has a misorientation frequency close to normal distribution, while for sample deformed at $10 \%$ an increase of frequency at low angles $\left(2^{\circ}\right.$ to $\left.15^{\circ}\right)$ as well as at high angle $\left(50^{\circ}\right.$ to $\left.60^{\circ}\right)$ is observed (Figure 3b). This tendency is maintained in other treatment conditions, with the occurrence of the highest frequency of low angle in the sample deformed at $25 \%$. This result, reinforced by SEM images, shows that change
Table 1. Frequency of occurrence of CSL boundaries and hardness Vickers for various deformation conditions.

\begin{tabular}{ccccc}
\hline \multirow{2}{*}{ Def. (\%) } & \multicolumn{4}{c}{$\begin{array}{c}\text { CSL boundaries type (\%) } \\
\text { and Hardness (HV) }\end{array}$} \\
\cline { 2 - 5 } & *CSL & $\Sigma \mathbf{3}$ & $\Sigma \mathbf{3} / \mathbf{C S L}$ & Hardness \\
\hline As-received & 12.1 & 3.5 & 29 & 265 \\
10 & 16.2 & 7.0 & 43 & 313 \\
35 & 12.9 & 5.7 & 44 & 403 \\
\hline
\end{tabular}

*CSL corresponds to the total quantity of CSL boundaries.

in misorientation profile is highly influenced by plastic deformation, which also encourages austenite nucleation and formation of subunits in acicular ferrite ${ }^{6}$.

The increase of frequency in low angle indicates the refinement of the structure ${ }^{12}$ with the presence of crystallographic packages of acicular ferrite with misorientation degree between them of about $5^{\circ}$, and subunits with misorientation angle $e^{5,12}$ from $1^{\circ}$ to $2^{\circ}$. It was also identified changes in hardness, crescent with the level of deformation (Table 1) that, in steels with acicular microstructure, can be attributed to the high presence of misorientation angle ${ }^{12}$ up to $3^{\circ}$.

Thermomechanical treatment increased the occurrence of CSL boundaries, particularly $\Sigma 3$ type, in all conditions of treatment, as detected in (Figure 3d) when compared to the as-received material (Figure 3c). The $\Sigma 3 /$ total CSL rate of $28.7 \%$ in the as-received steel rises to $43.3 \%$ in the sample subjected to $10 \%$ strain (Table 1) and remains at high level 

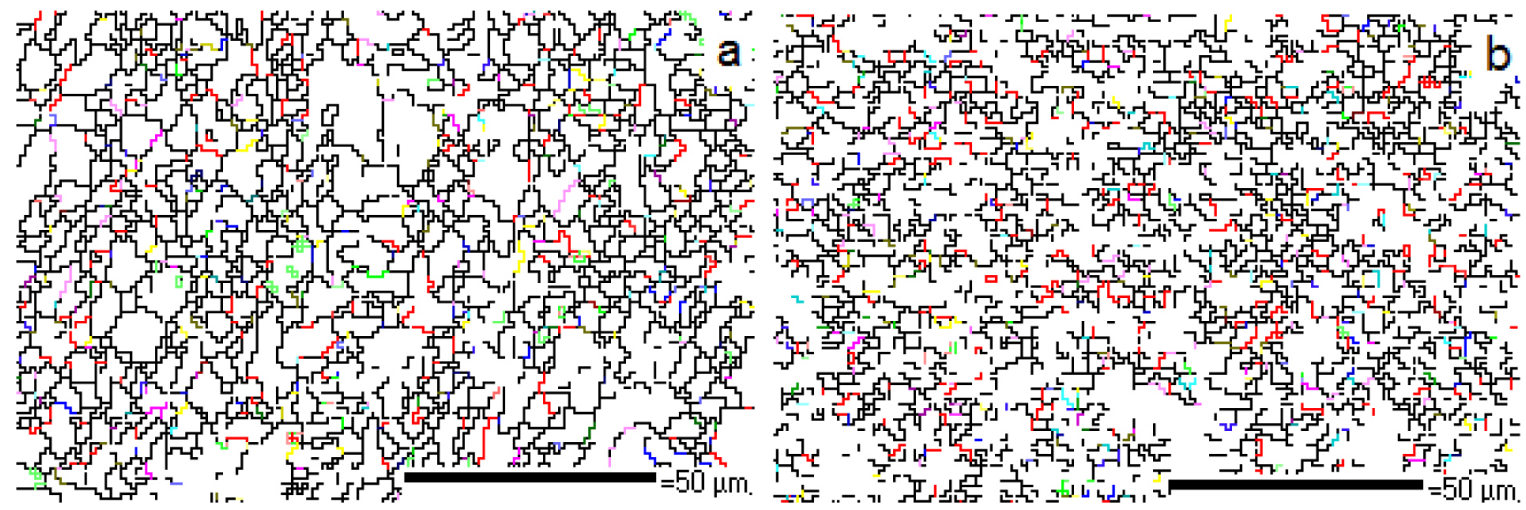

Figure 2. Grain boundaries (in black) and CSL boundaries (in color): (a) as-received steel (b) steel submitted to thermomechanical treatment deformed at $35 \%$.
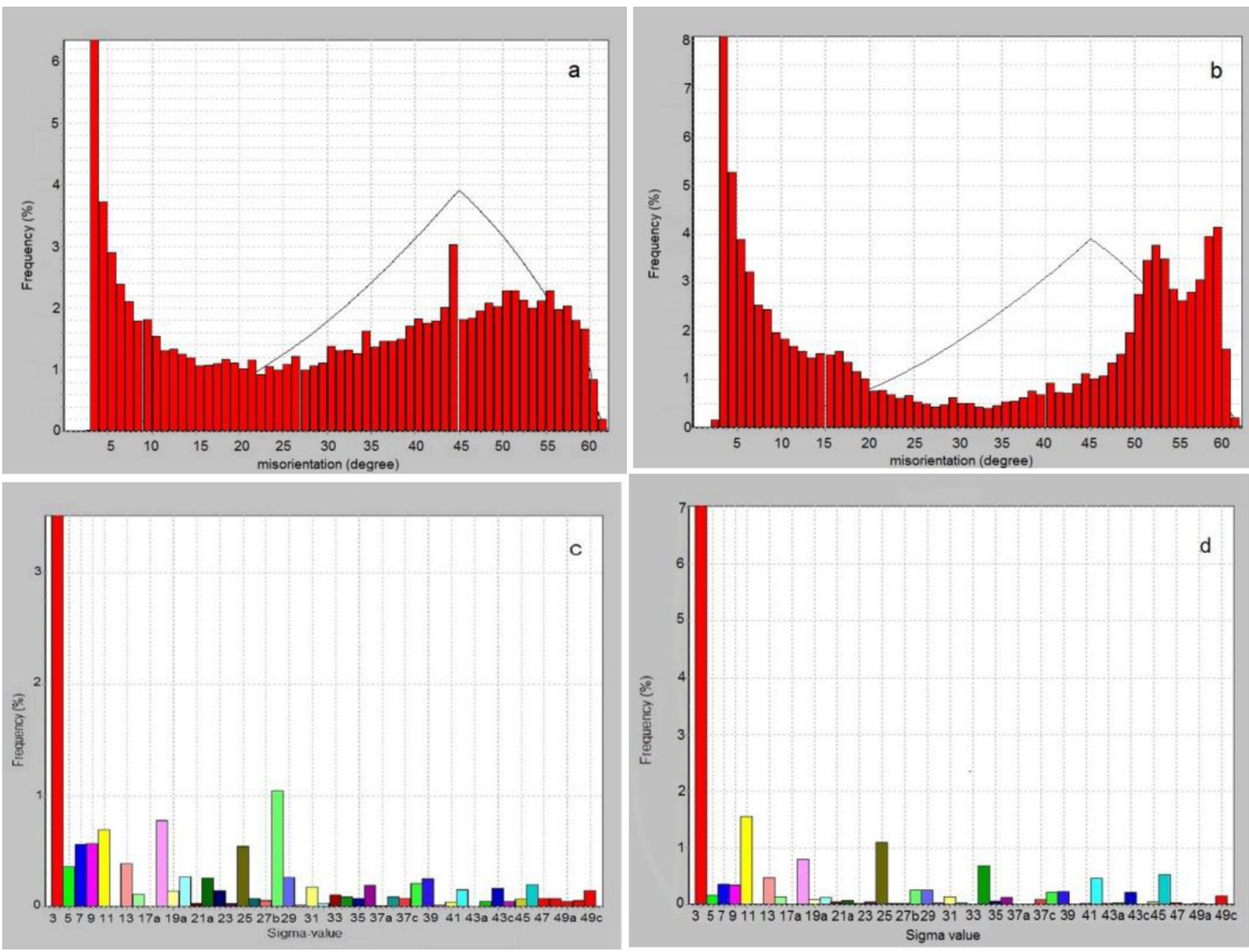

Figure 3. Misorientation profile: (a) as-received, (b) deformed at 10\% and CSL boundaries distribution: (c) as-received, (d).

for greater deformations, indicating that the mechanism of deformation is an important factor in shaping $\Sigma 3$ boundaries.

It was detected some relationship between the profile of disorientation and the occurrence of CSL boundaries. Considering that in CCC lattices the $\Sigma 3$ boundaries are generated by the rotation angle of $60^{\circ}$ of the plane $<111>$, it is expected that, due to $\Sigma 3$ increase, there should be an equivalent increment of frequency in misorientation profile close to $60^{\circ}$. In the as-received steel, misorientation frequency between $58-60^{\circ}$ corresponds only to $5.6 \%$ of total CSL boundaries while in the sample deformed at $10 \%$ (where there is high increase of $\Sigma 3$ boundaries) this frequency rises to $11.4 \%$, computing a variation of $5,8 \%$ (Table 2). Samples subjected to greater deformation also presented increases of $\Sigma 3$ boundaries and misorientations around $60^{\circ}$ when compared to non treated samples.

As for $\Sigma 3$ boundaries, modification of quantity of other $\Sigma$ boundaries can be detected by changes of misorientation profile. Table 2 shows the variation of occurrence of CSL boundaries and respective modification of misorientation 
Table 2. Variation of quantity of CSL boundaries and modification of quantity of boundaries around specific angle of $\Sigma$-symmetries.

\begin{tabular}{lcccl}
\hline \multicolumn{3}{c}{ CSL Identification } & \multicolumn{2}{c}{ *Variation } \\
\hline \multirow{2}{*}{$\Sigma$} & Axis & Angle & CSL (\%) & Boundaries(\%) \\
\cline { 3 - 5 } & & & As-received & $\mathbf{1 0 \%}$ deformed \\
\hline 3 & 111 & 60.0 & 14.6 & 5.8 \\
5 & 100 & 36.9 & -1.3 & -4.9 \\
7 & 111 & 38.2 & -2.5 & -5.4 \\
9 & 110 & 38.9 & -2.7 & -5.3 \\
11 & 110 & 50.5 & 4.0 & 2.0 \\
\hline \multirow{2}{*}{$*$} & &
\end{tabular}

profile around specific angle for each $\Sigma$-symmetry. The increase of frequency of $\Sigma 3$ and $\Sigma 11$ boundaries, as well as the reduction of $\Sigma 5, \Sigma 7$ and $\Sigma 9$ boundaries detected in $10 \%$ deformed samples, compared to not treated one, have respective variations on misorientation profile (Table 2). This modification was also detected for $25 \%$ and $35 \%$ deformation conditions.

Variation in misorientation profile can be clearly detected with the comparison between histograms of Figure $3 \mathrm{a}$ and Figure $3 \mathrm{~b}$. The reduction of $\Sigma 5, \Sigma 7$ and $\Sigma 9$ boundaries is verified by means of decrease in the frequency of misorienteation degree from $33.5^{\circ}$ to $41.5^{\circ}$ in misorientation profile, while the increase of boundaries of $\Sigma 11$ type is revealed with the increasing frequency misorientation around $50^{\circ}$ (Figure $3 \mathrm{~b}$ ).

According to Arafin ${ }^{3}$ and Gadzer et al. ${ }^{13}$, the increasing fraction of special boundaries has significant influence on the properties of the material. Low angle boundaries, as well as CSL's with low $\Sigma$ value are inactive and more resistant to intragranular fracture than high energy random boundaries ${ }^{14}$. Thus it is expected that the sample subjected to thermomechanical treatment with deformation of $25 \%$ shows the highest resistance to intragranular fracture since it combines a high fraction of $\Sigma 3$ boundaries (Table 1) with low occurrence of contours with $\Sigma>29$. Suzuky et al. ${ }^{1}$ found not only the importance of low $\Sigma$ boundaries in metallic materials, but also measured their limits of resistance by means of a method to evaluate the resistance of CSL boundaries. They compared the values of grain boundary fracture strength, in a Cr-Ni alloy, for different types of CSL boundaries and achieved that $\Sigma 3$ type presented the greatest value of strength, while $\Sigma 5, \Sigma 9, \Sigma 7$ and $\Sigma 11$ had decreasing values in this order.

Considering the results of Suzuky ${ }^{1}$, the significant increase from $3.5 \%$ to $7.1 \%$ of $\Sigma 3$ boundaries, in sample deformed at $10 \%$ (Table 1), should increase the strength of the material. However, the decrease of the amounts of $\Sigma 5$, $\Sigma 7, \Sigma 9$ boundaries, weaker than $\Sigma 3$, can decrease this benefit which was not totally evaluated by that author.

The finding of high fracture strength in $\Sigma 3$ boundaries for $\mathrm{Cr}-\mathrm{Ni}$ alloys ${ }^{1}$ reinforces the positive influence of the thermomechanical treatment on HSLA steels. Once applied, this treatment caused significant increase in $\Sigma 3$ boundaries in all samples, when compared to the as-received material. It was also observed, in intragranular regions of treated

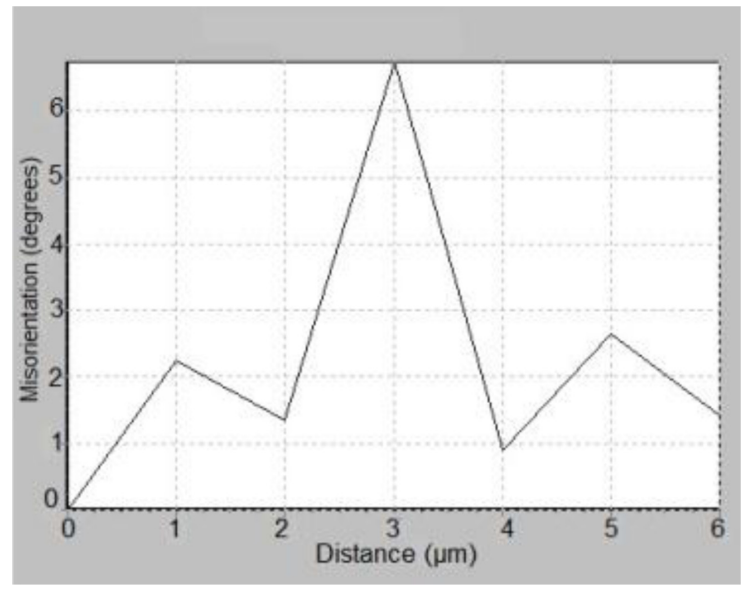

Figure 4. Intragranular misorientation profile shows twin boundaries aspect detected in sample deformed at $25 \%$.

samples, the presence of twin events (Figure 4). This phenomenon is a favorable factor to the formation of special type of boundaries ${ }^{2}$ and separates regions of symmetric misorientations, named as twins.

Some studies related to the occurrence of CSL boundaries show the effect of annealing treatments to stimulate or inhibit the formation of special boundaries ${ }^{15,16}$. However no studies were found reporting the effect of thermomechanical treatment on the formation of CSLs in HSLA steels. Randle ${ }^{16}$, when investigated the mechanism of formation of CSL boundaries stimulated by annealing, presented a model called " $\Sigma 3$ regeneration" which shows that the mobility of CSL boundaries, causes interactions among these types of boundaries which, depending on its nature, results in predominant $\Sigma 3$ boundaries type. According to this model, a $\Sigma 3$ boundary when meeting a $\Sigma 9$, also highly presented in cubic lattices, originates a new $\Sigma 3$ boundary, just as meeting a $\Sigma 9$ and $\Sigma 27$ also originate a $\Sigma 3$. This phenomenon would explain the fact that $\Sigma 3$ boundaries are highly present in treated samples.

Despite that the treatment applied here does not involve annealing process to allow high mobility of boundaries by diffusion, it is observed that plastic deformation in thermomechanical treatment has an important role in forming CSL boundaries. The movement of preferred slip planes and the interaction between dislocations during strain or shear transformations favor the mobility of boundaries and their interaction in forming new CSL boundaries.

\section{Conclusions}

By thermomechanical treatment, at non-recristalization temperature of austenite, it is possible to obtain dominant acicular ferrite microstructure in HSLA steel. Higher levels of deformation result in higher resistance level revealed by the increase in hardness of treated samples. This treatment modifies the misorientation profile, increasing low and high angle frequencies, tending to a bimodal distribution.

The Formation of CSL boundaries is influenced by thermomechanical treatment and it is possible to relate the 
modification of misorientation profile with the increase of $\Sigma 3$ and $\Sigma 11$ boundaries and inhibition of the formation of $\Sigma 5 \Sigma 7$ and $\Sigma 9$ boundaries. The formation of $\Sigma 3$ boundaries, beneficial to improve strength, is highly stimulated by this treatment where the intensity of deformation plays an important role in the development of special CSL boundaries. However further studies are needed to clarify this mechanism. Mapping of $\Sigma 3, \Sigma 9 \Sigma 27$ boundaries in

\section{References}

1. Suzuky A, Gigliotti MFX and Subramanian PR. Novel technique for evaluating grain boundary fracture strength in metallic materials. Scripta Materialia. 2011; 64:1063-1066. http://dx.doi.org/10.1016/j.scriptamat.2011.02.024

2. Kumar RB, Das SK, Mahato B and Das A. Chowshury GS. Effect of large strains on grain boundary character distribution in AISI 304L austenitic stainless steel. Materials Science and Engineering A. 2007; 454:239-244. http://dx.doi.org/10.1016/j. msea.2006.11.053

3. Arafin MA and Szpunar JA. A new understanding of intergranular stress corrosion cracking resistance of pipeline steel through grain boundary character and crystallographic texture studies. Corrosion Science. 2009; 51:119-128. http:// dx.doi.org/10.1016/j.corsci.2008.10.006

4. Tang $\mathrm{Z}$ and Stumpf W. The role of molybdenum additions and prior deformation on acicular ferrite formation in microalloyed Nb-Ti low-carbon line-pipe steels. Materials Characterization. 2008, 59:717-728.

5. Kim YM, Lee H and Kim NJ. Transformation behavior and microstructural characteristics of acicular ferrite in linepipe steels. Materials Science Engineering A. 2008, 478:361-370. http://dx.doi.org/10.1016/j.msea.2007.06.035

6. Lee $\mathrm{CH}$, Bhadeshia HKDH and Lee HC. Effect of plastic deformation on the formation of acicular ferrite. Materials Science Engineering A. 2003, 360:249-257. http://dx.doi. org/10.1016/S0921-5093(03)00477-5

7. Wang W, Shan W and Yang K. Study of high strength pipeline steels with different microstructures. Materials Science and Engineering A. 2009, 502:38-44. http://dx.doi.org/10.1016/j. msea.2008.10.042

8. Yang JH, Liu QY, Sun DB and Li XY. Microstructure and Transformation Characteristics of Acicular Ferrite in High Niobium-Bearing Microalloyed Steel. Journal of Iron and Steel Research. 2010, 17(6):53-59. http://dx.doi.org/10.1016/ S1006-706X(10)60114-8 different processing conditions associated with texture study by EBSD analysis are possible paths for further investigations.

\section{Acknowledgements}

The authors would like to thank FACEPE for financial support and the LME/LNNano for technical support during EBSD analysis.

9. Xiao F, Liao B, Ren D, Shan Y and Yang K. Acicular ferritic microstructure of a low-carbon Mn-Mo-Nb microalloyed pipeline steel. Materials Characterization. 2005, 54:305-314. http://dx.doi.org/10.1016/j.matchar.2004.12.011

10. Bhadeshia HKDH. The bainite transformation: unresolved issues. Materials Science Engineering A. 1999, 273-275:58-66. http://dx.doi.org/10.1016/S0921-5093(99)00289-0

11. Shanmugam S, Ramisetti NK, Misra RDK, Hartmann J and Jansto SG. Microstructure and High Strength-Toughness Combination of a New 700MPa Nb-Microalloyed Pipeline Steel. Materials Science and Engineering A. 2008, 478:26. http://dx.doi.org/10.1016/j.msea.2007.06.003

12. Guo A, Mirsa RDK, Liu J, Chen L, He X and Jansto SJ. Analysis of the microstructure of the heat-affected zone of an ultra-low carbon and niobium-bearing acicular ferrite steel using EBSD and its relationship to mechanical properties. Materials Science and Engineering A. 2010, 527:6440-6448. http://dx.doi.org/10.1016/j.msea.2010.06.092

13. Gazder AA, Cao W, Davies CHJ and Pereloma EV. An EBSD investigation of interstitial-free steel subjected to equal channel angular extrusion. Materials Science and Engineering A. 2008, 497:341-352. http://dx.doi.org/10.1016/j. msea.2008.07.030

14. Yu H. Influences of microstructure and texture on crack propagation path of X-70 acicular ferrite pipeline steel. Journal of University of Science and Technology. 2008, 15(6):683-687. http://dx.doi.org/10.1016/S1005-8850(08)60271-6

15. Fang X, Zhang K, Guo H, Wang W and Zhou B. Twin-induced grain boundary engineering in 304 stainless steel. Materials Science and Engineering A. 2008, 487:7-13. http://dx.doi. org/10.1016/j.msea.2007.09.075

16. Randle V. Mechanism of twinning-induced grain boundary engineering in low stacking-fault energy material. Acta Meterialia. 1999, 46(1)5:4187-4196. 